\title{
Study on Business Ethics Education of Financial and Economics Universities in China
}

\author{
Hua-Liang LU ${ }^{1, a,{ }^{*}}$ Qiu-Yu YE ${ }^{1, b}$, and Ya-Jun SUN ${ }^{1, c}$ \\ ${ }^{1}$ School of Business Administration, Nanjing University of Finance and Economics, Nanjing, China

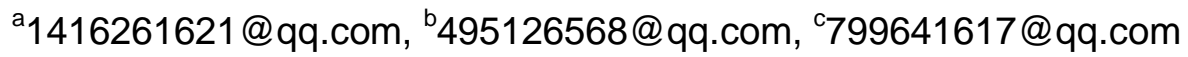 \\ *Corresponding author
}

Keywords: Financial and economics, Universities and colleges, Business ethics, Education, China

\begin{abstract}
Nowadays, the increasingly serious business ethical issues lead up to the highly concern of the society. The financial and economics universities and colleges take the main position for cultivating future commercial talents of the society. It is their responsibilities to study problems of business ethics education and to improve the ethical and moral standards of students. This article clarifies the importance and the necessity of conducting business ethics education in financial and economics universities and colleges in China, analyzes the status quo of business ethics education, and puts forward countermeasures and practices for the improvement of business and ethical education in Chinese financial and economics universities and colleges.
\end{abstract}

\section{Introduction}

Business ethics is the social interaction between mankind and society, reflecting the standard of expectation between people. In today's society, with the continuous emergence of commercial scandals, people are paying more and more attention to business ethics issues. It is well known that the food safety scandals such as "Sudan red" and "Melamine milk powder" have been continuously exposed by the media and arousing public panic [3].

Enterprises and society are in need of employees with high level of moral and ethical quality, and managers with high level of ethical decision-making skills. Graduates from financial and economics universities and colleges are the future managers of enterprises. The level of students' ethical standards will not only affect the development of their personal career, but also affect the development of socialist market economy and the success or failure of socialist moral construction. Therefore, business ethics education should be brought into higher education, especially financial and economics universities and colleges in China.

\section{The Importance and Necessity of Business Ethics Education in Financial and Economics Universities}

\section{The Need to Develop Students' Professional Ethics}

With China's accession to the WTO, commercial globalization has become an overwhelming inevitable trend. Compared with the past, modern commerce has changed in many aspects, including business environment, mode of operation and business philosophy. The most prominent of these are business ethics has become one of the mainstream values pursued by business operators. Business is an industry in a constantly changing environment, and business ethics education should also be self-improvement and development based on the ever-changing business. The financial and economics universities are the bases for cultivating business talents. The continuous improvement of the students' ethics quality helps to promote commodity trading and improve service quality, it is conducive to the effective operation and sustainable development of enterprises in the future, and is beneficial to the improvement of the whole social ethics atmosphere.

The United States started the study of business ethics earlier in the country. During the outbreak of the science and technology revolution, the U.S. industrial and commercial enterprises exposed economic scandals such as fraud, fraudulent transactions, corruption and bribery, which aroused 
people's deep consideration. With the help of this crisis, In November 1974, the first Economic Ethics Symposium held at the University of Kansas promoted the birth of business ethics. Since then, business ethics has entered an all-round development stage. In 1985, the American Business School's authority, the American Business School Confederation, expressly stated that business school must teach business ethics. After that, most schools in the United States opened the course of business ethics. In 1993, business ethics swept across the west, and the business ethics fever started in western universities and enterprises. During this period, business ethics courses were not only set up in universities, but also trained for employees [6].

Compared with the West countries, China's progress in the field of business ethics seems to be relatively slow. In order to adapt to the development of the socialist market economy, financial and economics universities should actively set up a business ethics education system specifically aimed at college students, critically inherit the traditional business ethics, We should cultivate students' correct professional ethics and sense of justice and interests, cultivate their conscientious work attitude and civilized behavior standards, improve their professional ethics and prepare for them to become qualified business people as early as possible.

\section{The Need to Improve the Personality of College Students}

Since ancient times, people have always tended to use ethics as a measure of the norms of a person's behavior. If a person loses his ethics, he will make the wrong ethical choice and find it hard to achieve his own career and life value, even bring loss to the society and be strongly condemned by the society. The incorporation of business ethics education into the educational system of financial and economics universities is an inevitable trend of the development of socialist market economy. It is also the need of self-development of modern business ethics education and an important prerequisite for the healthy growth of college students [7]. At the university stage, it is an important period for adolescents to form a correct outlook on life, values and world outlook. It has a high plasticity in cultivating ethics and morality. Schools should strengthen ethics and moral education for college students and improve their morality through education. It is an important mission of quality education and higher education for financial and economics universities to make students become commercial talents with high moral cultivation and better professional quality.

\section{The Need to Maintain the Order of the Market Economy and Standardize The Behavior of The Commercial Subject}

Under the background of socialist market economy, the main body of commerce should take the material and cultural needs of the people as its goal, and obtain the economic benefits in a reasonable and ethical way. No matter when and where, business entities should be based on the overall social interests. The individual interests of the commercial subject cannot exceed the overall interests and should unconditionally obey the interests of the entire society. Business entities should abide by the principle of equal trade, mutual benefit in the transaction and pay attention to credit and exchange with its competitors equally. Popularize business ethics education in financial and economics universities, set up a system of business ethics courses, and train graduates with the correct business ethics guidance, which can make it clear which behaviors are feasible and not feasible to achieve the purpose of regulating the behavior of the commercial subject. The purpose of the principal act can effectively overcome the negative effects brought by the limitations and negativity of the market economy and better safeguard the order of the socialist market economy.

\section{The Status Quo of Business Ethics Education for Students in Financial and Economics Universities}

\section{The Ethics Curriculum System Is Imperfect, and Ethics Education Popularity Is not High}

Based on the information of 46 financial and economics universities from "2017 China University Evaluation Research Report" published by China Alumni Network, we collected curriculum settings by visiting universities' official website. We found that the courses system of business ethics 
education in financial and economics universities in in general is not perfect and the popularization degree is generally low [11]. Among the surveyed 46 financial and economics universities, only one university in Dongbei University of Finance and Economics takes business ethics-related courses as compulsory courses; Another eight other universities have business ethics-related courses as optional courses. The rest $81 \%$ of the universities do not have courses in business ethics so far.

\section{The Educational Method is Traditional and Is Less Connected to Business Practice}

Business ethics education should be the unity of seeking knowledge and enlightenment. At present, the educational methods of business ethics education in financial and economics universities in China are rather backward [8]. They mostly follow the traditional, closed, and rigid classroom teaching. There is lack of connections to business practice. This collective instillation of classroom teaching not only makes the teachers themselves feel that the content they teach is very empty and has no substantive effect, but also makes the students feel dull and even produce confrontational psychology and suppress the enthusiasm and creativity of students' learning [2]. When the course is finished, the students' knowledge of business ethics is tested in the form of theoretical tests, and the students' business ethics are measured by test scores. However, students still use traditional methods of rote learning and repetition to deal with their examination. Outside the classroom, more ways to impart knowledge are also limited to course-related knowledge contests. The training mode of the school neglects the inner demand of students, ignores the need of combining theory with practice, equates the business ethics education with pure knowledge transfer, it is difficult to really improve students' ethics and moral standards and arouse students' sense of social responsibility, It is difficult to truly cultivate students' ethical perception and improve students' ethical decision-making ability.

\section{The Lack of Faculty and Supporting Resources}

Business ethics is a comprehensive interdisciplinary, which puts forward high requirements on the quality of teachers. It not only needs to master the professional knowledge such as philosophy, ethics, sociology and ethics analysis and decision-making ability, but also grasp the relevant content and skills of economics and management. China's financial and economics universities in the field of business ethics has not yet formed a professional teacher force [5]. Few teachers have both ethics and business knowledge. Most teachers with business professional knowledge do not have a solid foundation of ethics, and lack of theoretical research related to ethics. As for the theoretical schools of ethics, the development process and the basic content fail to reach the level of ethics professional teachers. Therefore, ethical knowledge is only by-passed, making students unable to really grasp the essence of ethical spirit and ethics analysis. Teachers with professional knowledge of ethics may lack the basic logic and knowledge related to business, and cannot reach the height of professional teachers in business science, rendering their teaching content too abstract and unable to provide in-depth explanations in conjunction with actual business cases, leaving students unable to fully grasp the essence of business ethics.

Second, the relevant teaching of financial and economics universities are market-oriented, with strong utilitarianism, the teachers of business ethics differ from the business teachers in capital support and resource allocation, no organizational support can be compared with other main courses, it has not been given the due attention, and its payment is not proportional to the return. As a result, teachers' interest in the study of business ethics is greatly reduced, and they seldom put into the teaching and research of business ethics.

\section{The Countermeasures to Improve Business Ethics Education for Students in Financial and Economics Universities and Colleges}

\section{Improving the Curriculum System and Enhancing Popularity of Ethics Education}

According to the setting of business ethics education curriculum in financial and economics universities in our country, we can improve the curriculum system and popularize the business ethics education from the following aspects: First, take the business ethics education as a compulsory course 
to improve students' attitudes to business ethics. Second, you can incorporate the content of business ethics into some of the other management classes and combine business ethics with these classes [9]. Thirdly, let the education of business ethics runs through all stages from lower grades to upper grades. Because the formation of business ethics awareness and the improvement of ethical standards are a gradual process, the cultivation and improvement of students' ethical decision-making ability are not accomplished in a single step. While improving the curriculum system, schools can also combine business ethics education with campus culture, which makes the business ethics infiltrated into the students' daily study life, and then influence the students imperceptibly. In addition to students, teachers should lead by example in setting up ethical and ethical campus culture to form correct ethical values. Campus culture in financial and economics universities may have strong utilitarianism, so the campus culture with business ethics needs the joint efforts of teachers and students.

\section{Innovating Educational Methods and Combining Theory with Reality}

The essence of business ethics is the student's creative interpretation of business knowledge and ethics as a participant in self-learning, self-organization and self-decision making in a concrete business context. According to the characteristics of business ethics, if financial and economics universities want to promote business ethics education and cultivate business personnel with higher ethics and higher professional qualifications and skills, it is necessary for them to abandon the traditional "one-word-one" education method, following the theory with practice, combining ethics and economic efficiency, taking problems and actions as the teaching principles and innovating business ethics education methods. Financial and economics universities can combine lectures, case discussions, practical activities and other methods according to teaching arrangements, and can also introduce more flexible and open foreign teaching methods to improve the students' interest in learning business ethics and the teaching effect of business ethics education so as to achieve the goal of high efficiency business ethics education.

\section{Fostering High-Quality Faculty and Providing Relevant Resources Guarantee}

In order to improve the shortage of teachers in business ethics education, financial and economics universities should provide relevant resources guarantee in business ethics education, and urge scholars including academic disciplines such as philosophy, ethics, economics and management to join the study of business ethics, and discuss ethical theory and ethical practices in business activities in order to foster high-quality business ethics faculty.

Business ethics related courses can be included in the curriculum of the business program; universities can also increase investment in teaching funds and resources to strengthen contacts between teachers and businesses to ensure that business ethics teaching have adequate funds and resources. Re-estimate and revise the contents and standards of the evaluation system of business ethics education, establish a fair and reasonable evaluation mechanism and attract more high-quality teachers to join business ethics education [10]. In addition, financial and economics universities may also set up business ethics education and research organizations, providing teachers with teaching guidance and regular teaching seminars to promote business ethics teachers and management, ethics and other professional teachers to exchange discussions, to carry out cooperative teaching, to increase teaching experience and to improve teaching effectiveness. Finally, the relevant organizations can build a network platform, with which teachers can share teaching resources through the platform and achieve complementary advantages.

\section{Acknowledgement}

Authors are grateful to the financial support from Natural Science Foundation of China (71773046), Jiangsu Social Science Foundation (16HQ014), Higher Education Philosophy and Social Science Research Fund of Education Department of Jiangsu Province (2017ZDIXM061), The Higher Education Reform Research Project of Jiangsu Province (2015JSJG035) The 13th 5-year Key Project of Jiangsu Education Science (B-b/2016/01/23), Qing Lan Project of Higher Education of Jiangsu Province and Six Talent Peak Project of Jiangsu Province. 


\section{References}

[1] Wu Yi-Ming. Study on the Business Ethical Education of MBA in China Based on CSR. Jiangxi Youth Vocational College, 2009 (2): 33-35.

[2] WU Yong. Business Ethics Education in American Business School and Its Enlightenment. Jiangsu Shang Lun, 2005 (4): 32-33.

[3] Zhou Ying-jie. The Necessity and Countermeasures of Business Ethics Education for Business College Students. Education and Careers, 2009 (12): 73-74.

[4] Yu Guo-mei. MBA education in social responsibility education research [J].Shanghai Management Science, 2008 (5): 85-87.

[5] Wu Hong-mei. Study on the Popularization and Countermeasures of Business Ethics Education for Undergraduates in China. Journal of Huaiyin Teachers College, 2012 (4): 389-390.

[6] Shi Zu-jun. It is imperative to set up business ethics course in higher business colleges. Journal of Hunan Business College, 2004 (04): 110-112.

[7] Chen Li. The Current Situation and Countermeasures of Undergraduate Accounting Ethics Education in China [J].Education and Teaching Forum, 2013 (48):264-265.

[8] Xia Yu,Liu Fu-yao. On the Cultivation of College Students' Professional Ethics. Employment Guidance, 2013 (1):76-78.

[9] BAO Fen, FENG Chen-yu, LIU Dong-jie, MENG Qing-peng. Optimization of Economics and Business Administration for Business Ethics Curriculum. Journal of Tianjin Business College, 2016 (1):83-84.

[10] Hu Guo-dong. Innovation of Business Ethics Teaching Reform in Business Administration: From the Perspective of Postmodernism. Education and Teaching Forum,2015 (14):88-89.

[11] Sun Ya-jun. Study on the Impact of Business Ethics Education in Financial and Economics Universities on the Orientation of Corporate Social Responsibility. Nanjing: Nanjing University of Finance and Economics, 2014. 